Artículo

\title{
La integración comercial de América Latina en el espejo del Pacífico, 1870-1920*
}

\author{
Marc Badia-Miró** (ID \\ Universitat de Barcelona. Centre d’Estudis Antoni de Capmany d’Economia i Història Econòmica. Barcelona Economic Analysis Team
}

\author{
Anna Carreras-Marín (D) \\ Universitat de Barcelona. Centre d'Estudis Antoni de Capmany d’Economia i Història Econòmica. Barcelona Economic Analysis Team
}

\section{Guillermo Martínez-Taberner (ID \\ Universitat Pompeu Fabra. Grup de Recerca GRIMSE}

\section{INFORMACIÓN DEL ARTÍCULO}

\section{Historia del artículo:}

Recibido: 26 de septiembre de 2020

Aceptado: 23 de junio de 2021

On-line: 5 de octubre de 2021

\section{Códigos JEL:}

N15, N16, N55, N56, N75, N76

Palabras clave:

Integración comercial

Primera Globalización

Comercio en Asia-Pacífico

Comercio en América Latina

\section{R E S U M E N}

La integración de los países de Asia-Pacífico y de América Latina en los mercados internacionales durante la Primera Globalización (1870-1920) ha sido un tema ampliamente tratado en la bibliografía. La dependencia del mercado británico y el creciente viraje hacia los EE. UU. en el caso latinoamericano, o el comercio intraasiático y la expansión de Japón como nueva potencia regional en el caso de Asia-Pacífico, han sido temas destacados. Menor atención ha recibido la fallida integración entre países de América Latina, lo que contrasta con los numerosos estudios sobre la integración regional asiática. Nuestro objetivo es identificar el papel del potencial de mercado a la hora de explicar las trayectorias distintas de integración regional en América Latina y en Asia-Pacífico. Para ello, analizamos los casos de Japón, por un lado, y Chile y Perú, por el otro, a partir de los flujos comerciales y su composición geográfica.

C 2021 Asociación Española de Historia Económica
JEL classification:

N15, N16, N55, N56, N75, N76

Keywords:

Market integration

First Globalisation

Asia-Pacific trade

Latin America trade

\section{Regional trade integration of Latin America in the Pacific mirror, 1870-1920}

\begin{abstract}
A B S T R A C T
The integration of Asia-Pacific and Latin American countries to international markets during the First Globalisation (1870-1920) has been widely discussed in the literature. Dependence on the British market and the growing shift towards the US in the case of Latin America, or intra-Asian trade and the expansion of Japan as a new regional power in the case of Asia-Pacific, have been prominent topics. Less attention has been paid to the failed integration among Latin American countries, in contrast to the numerous studies on Asian regional integration. Our aim is to identify the role of market potential in explaining the different trajectories of regional integration in Latin America and the Asia-Pacific. To this end, we analyse the cases of Japan, on the one hand, and Chile and Peru, on the other, on the basis of trade flows and their geographical composition.
\end{abstract}

@ 2021 Asociación Española de Historia Económica

\footnotetext{
* Versiones preliminares de este documento han sido presentadas en el CLADHE-V y en el WEHC 2018. Agradecemos los comentarios recibidos por Agustina Rayes, José A. Peres-Cajías y Vicente Pinilla, además de los comentarios recibidos por los/las dos evaluadores/as y de Luís Felipe Zegarra, editor de la revista. Marc Badia Miró y Anna Carreras Marín agradecen el apoyo financiero del Ministerio de Ciencia, Innovación y Universidades (MCIU), la Agencia Estatal de Investigación (AEI) y el Fondo Europeo de Desarrollo Regional (FEDER) a través del proyecto PGC2018-095821-B-I00. También agradecemos el apoyo financiero del Gobierno de Cataluña a través del programa SGR (2017SGR14669). Asumimos la responsabilidad de los errores existentes.

** Autor para correspondencia. Correo electrónico:mbadia@ub.edu (Marc Badia-Miró).
} 


\section{Introducción}

El siglo xxı ha visto con sorpresa cómo el menor efecto de la crisis financiera mundial sobre el crecimiento de las nuevas potencias asiáticas fue debido en gran medida al fortalecimiento de las relaciones comerciales sur-sur. Ello ha impelido a incorporar una nueva perspectiva geográfica en los análisis del comercio internacional con la premisa de que no se trata simplemente de analizar los efectos de la integración comercial en los mercados internacionales de una forma aespacial, sino que también importa destacar la dimensión geográfica de dicha integración. Esta perspectiva no es nueva: tiene las raíces en las teorías centro-periferia de la década de 1960. La necesidad de incorporar la dimensión geográfica en los modelos económicos ha dado lugar al desarrollo de las nuevas teorías del comercio internacional y a la denominada nueva geografía económica. Considerando estas perspectivas, planteamos una comparativa entre las trayectorias divergentes de la integración regional de dos áreas bien diferenciadas. Por un lado, la formada por Japón y los países de Asia-Pacífico y, por otro, la formada por Chile y Perú y sus principales socios latinoamericanos, entre 1870 y 1920, y planteamos alguno de los factores explicativos de ese proceso.

Durante el período de estudio que abarca la denominada Primera Globalización, el grado de integración internacional de los países del Pacífico aumentó, tanto para los países de América Latina como para los países de la región Asia-Pacífico. Sin embargo, mientras en Asia se produjo la emergencia de Japón como una nueva potencia industrial, en la orilla americana los tímidos procesos industriales de Chile o Perú apenas se podrían calificar de industrialización incipiente.

La bibliografía en el campo de la historia económica de ambas regiones ha tratado en profundidad el papel de las exportaciones en el crecimiento económico y la intensidad que tuvieron los ciclos exportadores en el periodo anterior a la Primera Guerra Mundial (Bértola y Ocampo, 2012; Bulmer-Thomas, 2010; Findlay y O'Rourke, 2007; Kuntz-Ficker, 2017; O’Rourke y Williamson, 1999). Para América Latina, varios trabajos han subrayado la idea de extrema especialización del sector exportador, mientras otros trabajos han puesto el énfasis en la especialización geográfica de las exportaciones, poniendo de relieve el hecho que la mayor parte de las exportaciones latinoamericanas se dirigían a muy pocos destinos (Badia-Miró y Carreras-Marín, 2012; Bulmer-Thomas, 2010). Salvucci (2008) entre otros, ha señalado la existencia de determinados vínculos entre el crecimiento basado en las exportaciones y el impulso de la industrialización en buena parte de América Latina a través de la expansión de la demanda o a través de los encadenamientos entre sector exportador y sector manufacturero. Badia-Miró (2015) y Cariola Sutter y Sunkel (1983) han analizado este aspecto para Chile, Abreu y Bevilaqua (1996) lo han hecho para Brasil y Contreras (2009) para el caso peruano. Pese a la existencia de esos vínculos, la llegada de la Primera Guerra Mundial no alteró sustantivamente el escenario y el sector manufacturero no fue capaz de cubrir el vacío dejado por los principales países europeos (Albert, 1988; Carreras-Marín, Badía-Miró y Péres-Cajías, 2013).

En contraposición a ello, el caso japonés ilustra la exitosa transformación de una economía que pasó de ser exclusivamente exportadora de materias primas, tras la apertura del país a mediados del siglo xIx, a ser una economía mucho más diversificada desde finales de siglo, donde el peso de las manufacturas fue adquiriendo de forma progresiva cada vez mayor relevancia hasta la década de 1930 , de la mano de un intenso proceso de industrialización (Howe, 1996; Latham, 1994; Sugihara, 1990; Sugiyama, 1988). En concreto, Sugihara (1990) mostró, desde el punto de vista de la demanda, el vínculo existente entre las exportaciones de materias primas como la seda y el té con el desarrollo de la industria exportadora del algodón, por el efecto que tuvo sobre la demanda interna.

La transformación del modelo económico y la diversificación de las exportaciones niponas discurrieron en paralelo a un proceso de diversificación geográfica hacia países de su alrededor, sobre la base de esa expansión manufacturera. Este proceso se intensificó especialmente durante la Primera Guerra Mundial y en los años posteriores, debido a la caída de la competencia occidental, como resultado del incremento de los costes de transporte de sus competidores (Meissner y Tang, 2018). Por el contrario, Latinoamérica intensificó la especialización de la cesta exportadora, al calor de los ciclos del guano, del salitre y del cobre, profundizándose su fuerte dependencia de las primeras materias además de acentuar una mayor concentración en los destinos. En parte, esa enorme dependencia estuvo estrechamente ligada a los intentos no exitosos de establecer una industria manufacturera, capaz de sustentar un proceso de crecimiento económico endógeno que redujera la enorme volatilidad a la que estaban sometidas esas economías.

Los factores que pueden explicar esas trayectorias tan distintas son múltiples: desde un acceso diferencial a la tecnología; unas políticas proteccionistas que, en unos casos, pudieron favorecer el desarrollo de determinadas actividades manufactureras; un mejor acceso al capital doméstico y exterior; unos términos de intercambio más volátiles que incidieron de manera negativa sobre el crecimiento económico, o bien a la posible existencia de una mayor integración regional impulsada por un mejor acceso a un mercado de mayor tamaño (Duran, Musacchio Della Paolera, 2017; Gómez-Galvarriato y Williamson, 2009). Nuestro objetivo en este artículo es describir las tendencias divergentes entre la integración comercial en América Latina y en la zona de Asia-Pacífico, relacionándolas con este último aspecto señalado, es decir, con la distinta influencia que tuvo el potencial de mercado en ambas regiones. Para ello es necesario combinar el componente exterior y el componente doméstico del potencial de mercado. Por componente exterior entendemos la posibilidad de tener un acceso mayor al mercado exterior por estar cerca de economías de mayor tamaño, a medida que se reforzaban los lazos comerciales y los costes de transporte se reducían. Por componente doméstico entendemos el rol jugado por el tamaño del mercado nacional y su expansión, a medida que va produciéndose la integración del mercado doméstico con la reducción de los costes de transporte internos, el proceso de urbanización y la mejora de los salarios reales. En ese sentido, parece que en ambas regiones los salarios estancados, la desigualdad y los bajos niveles de vida en la mayor parte de la población pudieron lastrar el proceso de desarrollo (Bulmer-Thomas, 2010). Pero, en lo que se refiere al componente exterior, tal y como señalan recientemente autores como Meissner y Tang (2018), Japón pudo capitalizar el mayor tamaño de los países vecinos para exportar productos cada vez de mayor valor añadido. Es decir, en 
comparación con lo que sucedía en América Latina, el proceso de expansión comercial de Japón estaría relacionado con la mayor intensidad del proceso de integración regional asiático. Es por ello por lo que el presente trabajo se propone comparar el componente exterior del potencial de mercado de Japón, con el potencial de mercado de Chile y Perú, a partir de dimensionar el tamaño del mercado regional ${ }^{1}$.

El artículo se ha estructurado de la siguiente manera. Se inicia con un análisis comparado de los procesos de integración regional basado en las estadísticas comerciales oficiales de una muestra de países a ambas orillas del Pacífico: Japón, por un lado, y Chile y Perú por el otro. En segundo lugar, se cuantifica y compara el tamaño del potencial de mercado resultante de ese proceso de integración de ambas regiones, al ser una variable determinante a la hora de poder aprovechar la existencia de economías de escala en el sector manufacturero, y así favorecer el crecimiento y diversificación de las exportaciones. Finalmente, el artículo identifica otros factores explicativos que cabe destacar en base al análisis comparado de la muestra de países escogidos de ambas regiones del Pacífico. Se cierra el artículo con un apartado de conclusiones.

\section{El comercio intraregional a ambas orillas del Pacífico}

Durante la Primera Globalización, las exportaciones se expandieron en los tres países en paralelo a su integración a los mercados internacionales. Si comparamos los valores totales, comprobamos que la evolución de las exportaciones chilenas y las exportaciones japonesas fue parecida, al menos hasta mediados de la década de 1890 (véase figura 1). A partir de ese momento, las exportaciones japonesas mantuvieron una dinámica parecida a la observada en las décadas anteriores. Por el contrario, las exportaciones chilenas sufrieron un leve freno en su expansión y, aunque siguieron creciendo, lo hicieron a un ritmo inferior. Esta tendencia perduró hasta mediados de la década de 1900, momento en que se retomó la senda de crecimiento al calor de la intensificación del ciclo del salitre (Badia-Miró y Díaz-Bahamonde, 2017; Bermúdez, 1963). En cuanto a Perú, observamos algo parecido a lo visto en el ritmo de crecimiento de Japón, aunque los niveles de exportaciones fueron totalmente diferentes (Drinot, 2000; Seminario, 2015). Para obtener los valores del comercio regional se han considerado las exportaciones (o importaciones) a los países definidos para las dos áreas geográficas respecto al total de las exportaciones (o importaciones) $)^{2}$.

Aunque la evolución del comercio agregado ofrece información relevante sobre la expansión de estas economías en el medio y largo plazo, en este trabajo nos centramos únicamente en el papel que jugó el comercio regional de Japón con su entorno asiático, en comparación con el comportamiento de Chile y Perú con sus vecinos latinoamericanos. La idea es poder comparar la importancia que pudo tener la integración de ambas regiones a la hora de explicar el desarrollo divergente de sus economías. La figura 2 muestra que el peso que tenía el comercio regional con respecto al comercio exterior a mediados del siglo xix no se diferenciaba en exceso del que tuvo al inicio de la década de 1870 . Sin embargo, el devenir de la Primera Globalización determinó trayectorias absolutamente dispares. Si nos centramos en el caso chileno, observamos tres períodos claramente diferenciados: en el primero, entre 1873 y 1878, el comercio con los otros países de América Latina se situó de promedio en un $27 \%$; en el segundo

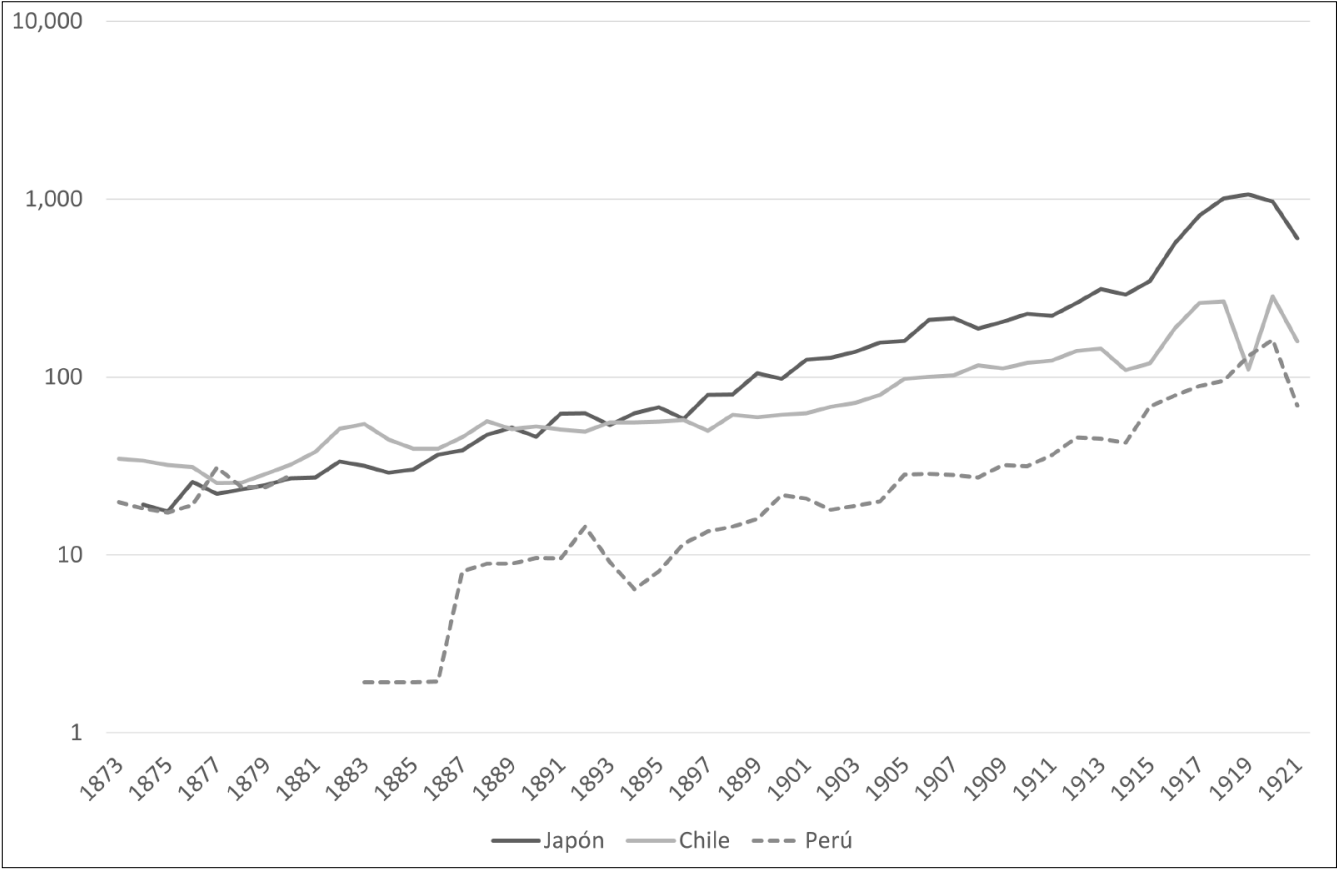

Figura 1. Evolución de las exportaciones totales de Japón, Chile y Perú (en \$US dólares corrientes).

Fuente: elaboración propia en base a estadísticas comerciales oficiales de cada uno de los países. Para más detalles, véase la lista de referencias de fuentes que aparecen en la bibliografía.

\footnotetext{
${ }^{1}$ No se incorpora el análisis detallado de la componente doméstica del potencial de mercado porque en el presente trabajo nos hemos enfocado en el impacto de los mercados regionales sobre el proceso de diversificación exportadora.
}

${ }^{2}$ Hemos definido como comercio regional el comercio que Chile o Perú realizan con el resto de América del Sur y el comercio de Japón con los países de la región de Asia-Pacífico, región que incluye en el caso del presente trabajo las zonas geográficas de Asia Oriental, sudeste Asiático y Asia Meridional. 


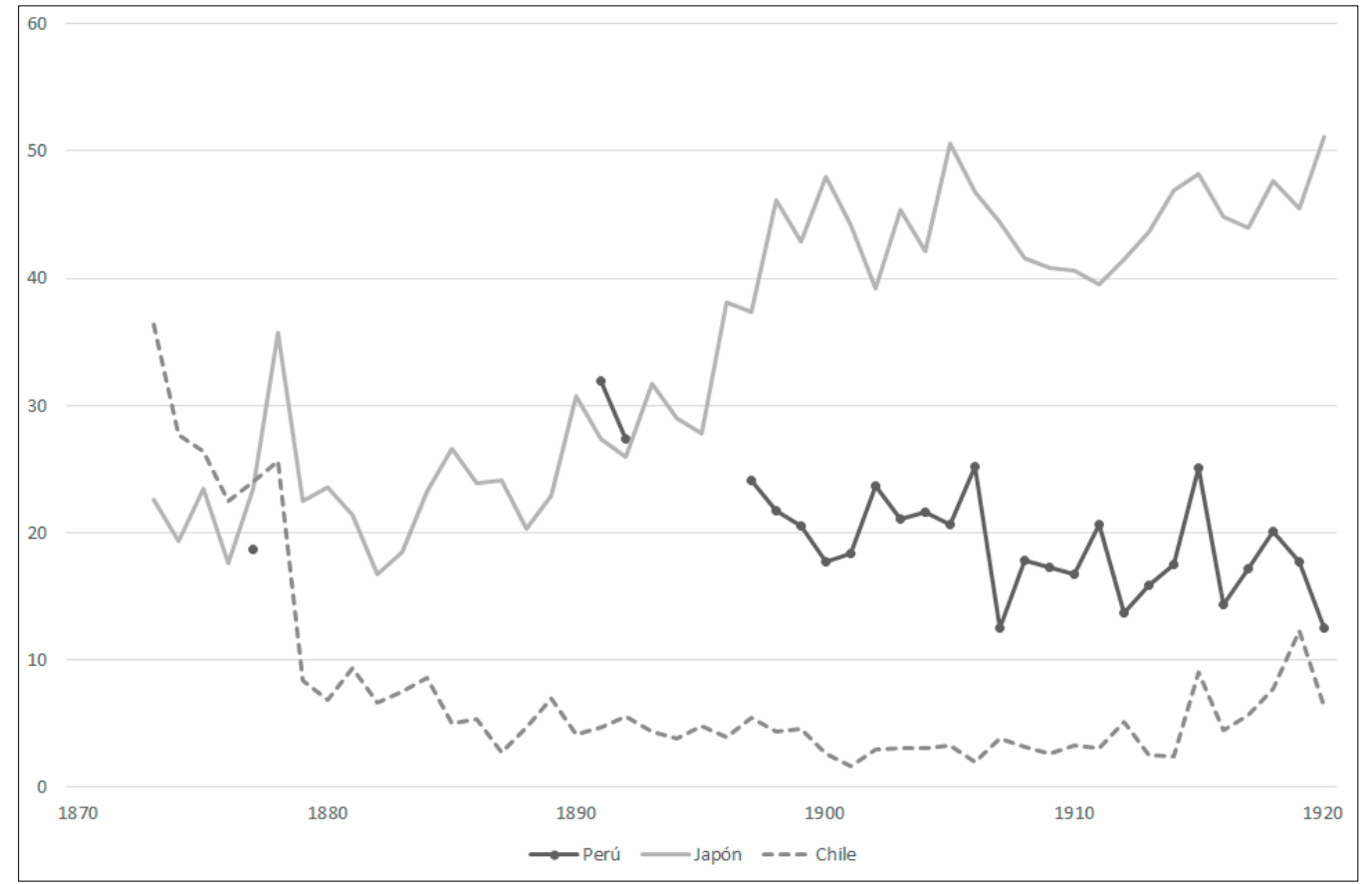

Figura 2. El peso del comercio intrarregional para Japón, Chile y Perú (\% sobre la exportación).

Fuente: elaboración propia en base a estadísticas comerciales oficiales de cada uno de los países. Para más detalles, véase la lista de referencias de fuentes que aparecen en la bibliografía. periodo, entre 1879 y 1914, el porcentaje se redujo al 4,5\% de promedio, resultado directo de la inestabilidad y los conflictos con sus principales socios regionales resultado directo de la Guerra del Pacífico; en una tercera fase, desde la Primera Guerra Mundial hasta 1920, el peso del comercio regional se recuperó ligeramente, llegando a suponer el 7,6\%. Aunque, tal y como hemos indicado, el impacto de la Guerra del Pacífico fue determinante, también parece claro que el proceso de especialización de las exportaciones basado en el impulso del salitre comportó una especialización geográfica notable, que tuvo como resultado una reducción considerable del peso del comercio intrarregional. De hecho, y esto es destacable, la caída en el comercio regional no solo se observó en términos relativos, sino que también lo fue en términos absolutos (Carreras-Marín, Badía-Miró y Péres-Cajías, 2013; Peres-Cajías et al., 2021). La escasez de datos de comercio bilateral para los primeros años en el caso de Perú hace difícil comparar la evolución del país en ese periodo y dificulta el establecimiento de una periodización clara. Sin embargo, a partir de evidencias indirectas, podemos confirmar que la trayectoria peruana parece que fue muy parecida a la observada en el caso chileno y, por lo tanto, mostraba valores parecidos para el comercio regional, situándose en un promedio del 19,7\% (Seminario, 2015; Zegarra, 2011).

Cuando nos centramos en el comercio regional japonés, observamos tendencias parecidas a las observadas para el caso chileno. Ello nos permite hablar también de la existencia de tres ciclos diferenciados a la hora de describir el comercio intrarregional. El primer periodo, entre 1873 y 1889 , mostraba valores ligeramente superiores a los observados en el caso chileno (de promedio, valores que rondaban el $22 \%$ ). En ese caso, a diferencia de lo observado en el caso latinoamericano, en la última década del siglo xix el comercio regional se aceleró, coincidiendo con la inserción de esta economía en los mercados internacionales y evolucionando en paralelo al desarrollo incipiente de su industria. Los registros obtenidos se situaron en valores cercanos al $30 \%$ de promedio coinci- diendo con el cambio de siglo, cuando el porcentaje comenzó a situarse por encima del $40 \%$. En líneas generales, a modo de comparación, podemos afirmar que los países atlánticos no comerciaron entre ellos en más de un cuarto o de un quinto del valor total. Esa tendencia sería parecida a la que se observó para Perú y Chile en un momento en que el comercio se expandió; es decir, el impulso exportador y la integración en los mercados internacionales se realizó con los países europeos.

Si repetimos el análisis, pero nos centramos en el comportamiento de las importaciones, observamos grandes similitudes (véase figura 3). En la década de 1870, los niveles de integración comercial japonesa con Asia eran similares a los que Chile y Perú mostraban para América Latina. Pero, tal y como sucedió con las exportaciones, se detecta la existencia de trayectorias distintas. Mientras que en el caso japonés la tendencia era claramente creciente, en los países latinoamericanos la tendencia era la contraria. Si miramos con mayor detalle la procedencia de las importaciones en el caso japonés, entre 1873 y 1889 en un $29 \%$ de promedio procedían del resto de países asiáticos, aumentando hasta valores que superaron el $44 \%$ a partir de 1890 . En el caso de los países latinoamericanos, la evolución de las importaciones regionales de Chile y Perú seguían una tendencia contraria. Perú mostraba una menor integración comercial que Chile, aunque a diferencia de su vecino experimentó un moderado repunte en las primeras décadas del siglo xx. Chile importaba de América Latina un $19 \%$ en promedio antes de la Guerra del Pacífico, y un $13 \%$ a partir de entonces. Perú lo hacía en un $11,4 \%$ de media antes de 1897, y en un 6,5\% desde 1897 hasta 1920. Una posible explicación serían los factores geográficos. Chile, aunque orientado al Pacífico, tenía vínculos con Argentina, la cual estaba creciendo y diversificando su economía y su sector exterior (Rayes, 2015); en cambio, Perú quedaba muy alejado de Argentina y del resto de países latinoamericanos, pudiéndose ver afectado por unos mayores costes de comercio con sus vecinos regionales. 


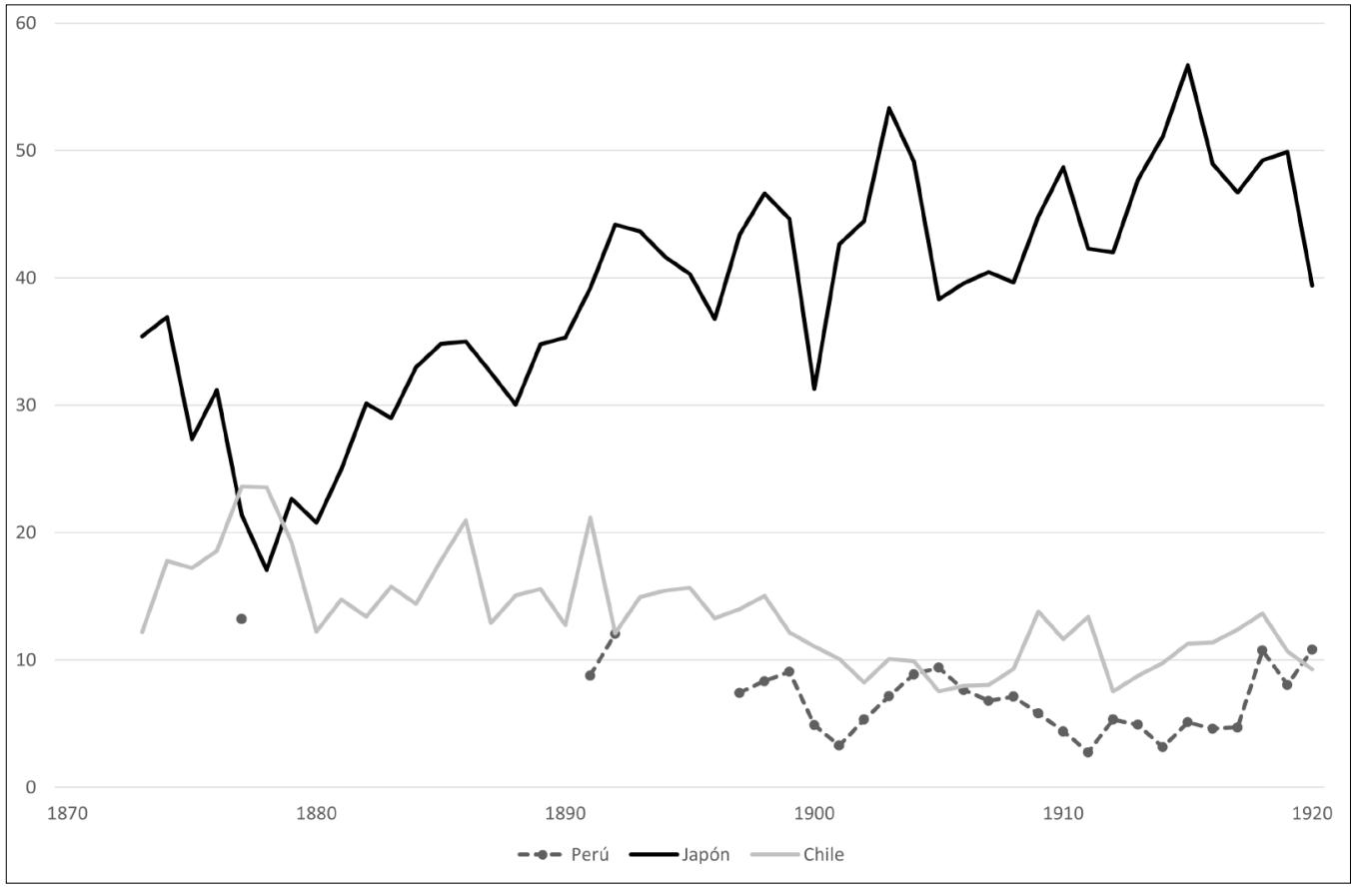

Figura 3. El peso del comercio intrarregional para Japón, Chile y Perú (\% sobre la importación).

Fuente: elaboración propia en base a estadísticas comerciales oficiales de cada uno de los países. Para más detalles, véase la lista de referencias de fuentes que aparecen en la bibliografía.

\section{Factores explicativos de la integración regional: el potencial de mercado}

Tal y como muestran Meissner y Tang (2018), una de las razones que habría detrás del proceso de expansión comercial japonés en los años previos a la Primera Guerra Mundial estaría relacionado directamente con la mayor intensidad del proceso de integración regional asiático que acompañaría la industrialización japonesa, sobre la base de la exportación de productos manufacturados de bajo valor añadido a los mercados asiáticos, así como el tamaño de estos mercados vecinos. Frente a ello, observamos una pérdida de impulso de la integración regional en América Latina, al menos hasta la Primera Guerra Mundial, en paralelo a una pérdida de peso de las exportaciones manufactureras de Chile y de Perú (que principalmente tenían como destino los mercados vecinos). Los niveles previos a la Guerra del Pacífico no se volvieron a recuperar, en paralelo a un proceso de intensificación de la especialización comercial, tanto por productos como por destinos.

Si bien es cierto que el conflicto resquebrajó el comercio bilateral entre Chile, Bolivia y Perú (Sater, 1986), creemos relevante introducir una nueva variable que nos permita explicar, de manera más completa, la existencia de esas notables trayectorias divergentes entre ambas regiones. Si seguimos los trabajos de Jacks y Novy (2018) vemos que existe una relación directa entre el potencial de mercado de los países y su posterior crecimiento económico. Siguiendo la metodología propuesta por Harris (1954), entendemos el potencial de mercado como aquella variable que considera la dimensión del mercado de un país, conjugando la importancia que tiene el mercado doméstico con la dimensión que tienen los mercados vecinos, corregidos por los costes de comerciar con ellos. Precisamente por la orientación exterior que tiene una parte del proceso de industrialización japonés, entendemos que esta variable fue crucial a la hora de hacer una correcta comparación entre ambas regiones.
En la figura 4 vemos, para 1910, la relación existente entre el potencial de mercado (Jacks y Novy, 2018) y la distancia al principal mercado, el Reino Unido. Si bien parece clara la relación negativa entre ambas variables, también observamos que Japón aparecería como un outlier en la muestra de países, con un potencial de mercado mucho mayor al esperado, teniendo en cuenta su lejanía a los mercados europeos. Esa diferencia era más notable al comparar los valores obtenidos para Japón con los observados para Latinoamérica. En ese sentido, Chile y Perú mostraban menor potencial de mercado, al igual que otros países de la región, mucho más grandes e integrados en los mercados internacionales como Argentina y Brasil. Aunque en ningún caso nos planteamos hablar de la existencia de una relación causal entre ambas variables, sí que afirmamos que el mayor potencial de mercado observado en Japón podría estar asociado a un fortalecimiento del proceso de integración regional, en paralelo al proceso de industrialización del país asiático, y a la inserción de estas economías a los mercados internacionales. Por lo tanto, podría decirse que la dimensión del mercado japonés y el de sus vecinos, sumado a la existencia de unos menores costes de transporte, favoreció la creación de unos mercados regionales que, ante la aparición de choques externos intensos que fracturaron el comercio internacional (como pudo ser la Primera Guerra Mundial), permitieron que los mercados fueran ocupados por las potencias industriales regionales. Una mayor productividad y una industrialización más intensa explicarían que con la llegada de los años 1920 se consolidase la presencia nipona en los mercados asiáticos. Por el contrario, aunque América Latina también impulsó su producción manufacturera y surgieron algunas experiencias exportadoras a los países vecinos durante los años de la Primera Guerra Mundial, las dificultades para abastecerse de materias primas y de maquinaria, junto a las restricciones financieras, el relativo atraso tecnológico y la falta de competitividad de la industria local, impidieron su consolidación en los años posteriores ante el retorno de los productos europeos y de los EE. UU. (Albert, 1988; Bulmer-Thomas, 2010). 


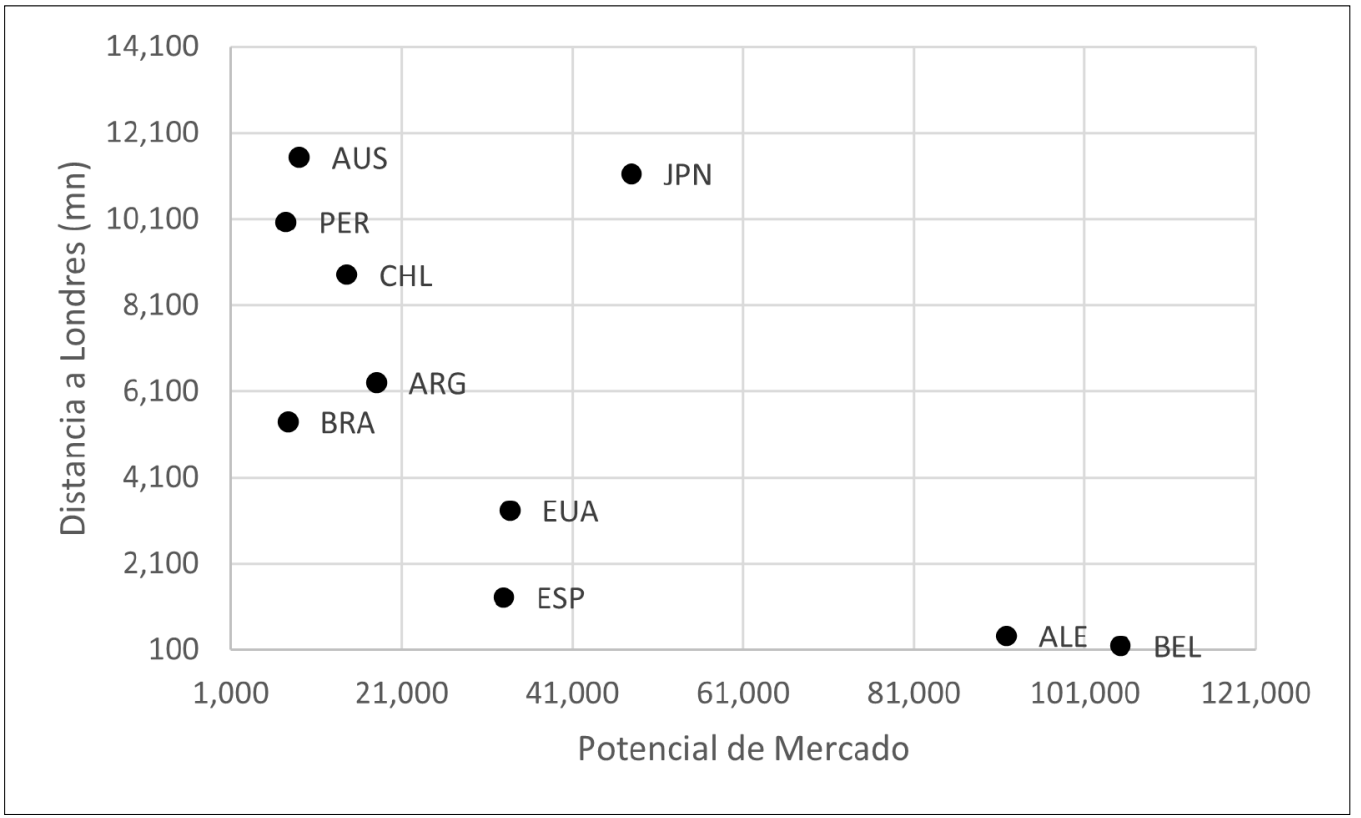

Figura 4. Potencial de mercado y distancia a Londres (Gran Bretaña), 1910.

Fuente: Jacks y Novy (2018) y distancias náuticas a partir de: https://sea-distances.org/
La mayor dimensión de las economías asiáticas explicaría una parte de ese mayor potencial de mercado que observamos para Japón, a pesar de la gran expansión de las economías latinoamericanas durante el periodo de la Primera Globalización. En 1870 la dimensión de las economías de la zona del este asiático era catorce veces la de América Latina, y en 1913 el tamaño de esas economías seguía siendo muy superior. A esa mayor dimensión se sumaría la existencia de unos menores costes de transporte que, en buena parte, se explicarían por las distancias menores entre Japón y sus mercados regionales, además de poderse realizar por vía marítima (la distancia entre los principales puertos asiáticos podía ser la mitad de la distancia que encontraríamos entre los principales puertos de América Latina).

\section{Otros factores explicativos de la diferente integración regional a ambas orillas del Pacífico}

El comercio regional apenas si aparece en la bibliografía sobre América Latina durante la Primera Globalización, en contraposición con el caso asiático. Más allá del trabajo de Assadourian (1982) sobre el comercio regional en la época colonial, ésta ha sido una cuestión que solo se empieza a tratar, de forma pionera, en los estudios de CEPAL a partir de los años 1950, con escaso seguimiento por parte de una bibliografía, focalizada sobre todo en explicar la integración (y la dependencia de la excesiva especialización) con los principales socios comerciales: Gran Bretaña, EE. UU. y Europa continental (Cardoso y Faletto, 1971; Cortés-Conde y Hunt, 1985; Dos Santos, 1970). Recientemente, el relativo avance de los acuerdos de cooperación comercial en la zona ha despertado el interés por el comercio regional, poniendo de relieve los múltiples obstáculos a la integración; pero su análisis se ha centrado en la evolución y los factores determinantes de los procesos de integración regional de fines del siglo xx (Devlin y Ffrench-Davis, 1999; ECLAC, 1998) o el impacto negativo que han tenido para la región los tradicionalmente elevados costes de transporte (Mesquita Moreira et al., 2008). Carreras-Marín, Badía-Miró y Péres-Cajías (2013) retrotrajeron el estudio del comercio regional hacia el pasado de América
Latina, centrándose en el Cono Sur en el período 1912-1950. Para el mismo periodo, Badia-Miró, Carreras-Marín y Meissner (2018) profundizaron en las causas del bajo comercio regional en el Cono Sur poniendo de relieve el peso de los costes del comercio, derivados tanto de las políticas comerciales implementadas por los distintos países como de elevados costes de transporte por deficientes infraestructuras de comunicación entre los países de la región. Por último, otro trabajo relevante es el de Restrepo Estrada (2017), que vincula la integración regional y el proceso de industrialización en Colombia durante el siglo xx.

Por el contrario, el papel crucial que tuvo la integración asiática en el crecimiento económico de la región es uno de los temas que mayor atención ha atraído desde finales del siglo xx. El término comercio intraasiático hace referencia a las relaciones comerciales entre los territorios situados en las regiones de Asia-Pacífico, pero su significado encierra una gran discusión, existiendo discrepancias relativas a sus implicaciones y a la aplicabilidad de este concepto a diferentes períodos históricos. Por un lado, algunos autores lo vinculan a la fase de expansión del nuevo imperialismo europeo y norteamericano en Asia, que abarca desde los años ochenta del siglo xix hasta la Primera Guerra Mundial. Se trata de autores como Sugihara (2005), quien consideraba que para referirse al comercio intraasiático es fundamental tomar en consideración el impacto de las potencias occidentales en la reorganización del comercio regional a través del imperialismo, sin dejar de tener en cuenta otros procesos del mismo período como la industrialización de Japón o el crecimiento de ciertas economías asiáticas. Por otro lado, desde la perspectiva de otros historiadores, Hamashita (2008) defendía que el origen de la esfera comercial que abarca la región de Asia oriental databa del siglo xvi y continuó hasta el siglo xIx, momento en el que se produjo la incorporación de las potencias occidentales y una intensificación de los flujos comerciales existentes. En cualquiera de los casos, los estudios académicos especializados en la historia económica asiática han mostrado el crecimiento del comercio intraasiático durante la Primera Globalización, así como el vínculo existente entre el desarrollo del comercio regional, la transformación de la economía japo- 


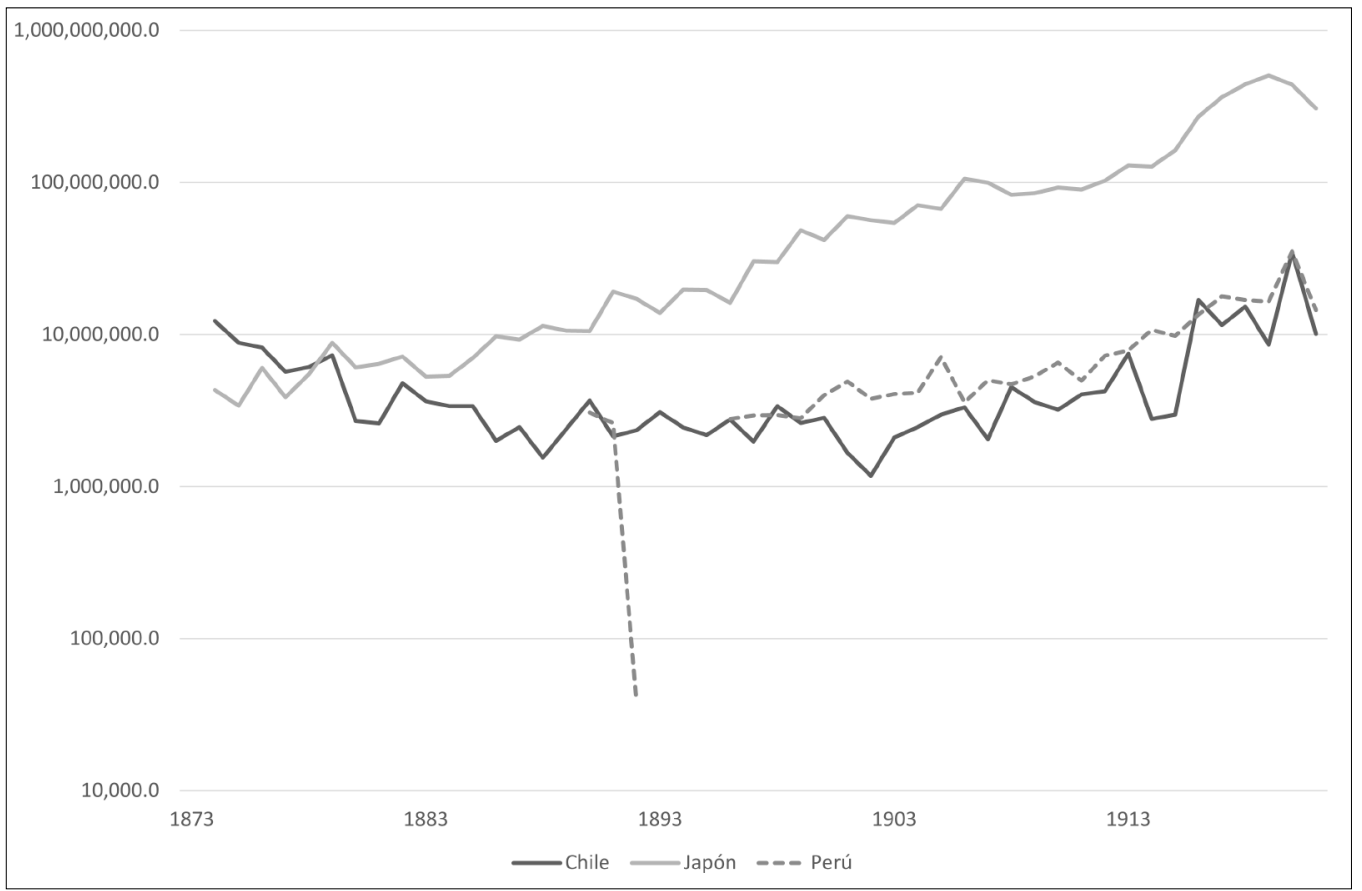

Figura 5. Exportaciones totales del comercio intrarregional de Chile, Perú y Japón, 1870-1921 (en \$US).

Fuente: elaboración propia en base a estadísticas comerciales oficiales de cada uno de los países. Para más detalles, véase la lista de referencias de fuentes que aparecen en la bibliografía. nesa y el rol del Gobierno nipón (Lockwood, 1954; Perkins y Tang, 2017; Schran, 1994; Tsunoyama, 1994)3.

A partir de aquí, el análisis comparado del desarrollo de la integración comercial de Chile, Perú y Japón nos permite identificar varios factores político económicos que ayudarían a entender las diferencias en el devenir del comercio regional de ambas áreas del Pacífico. La Guerra del Pacífico (1879-1884) resultó ser un punto de inflexión a la hora de entender las trayectorias divergentes existentes entre las economías latinoamericanas y Japón. El conflicto bélico comportó modificaciones en la estructura de las exportaciones, puesto que supuso, por un lado, la ocupación de los territorios donde se ubicaban los grandes yacimientos de salitre $y$, por el otro, la pérdida de mercados para una parte de la producción manufacturera local. En este caso, la exportación del salitre impulsó el crecimiento de las exportaciones chilenas, siendo su destino principal los mercados europeos y de los EE. UU. A ello se le sumó el conflicto político posterior que se agudizó con el paso de los años, deteriorándose así las redes comerciales previas existentes entre Chile, Perú y Bolivia, que habían existido desde tiempos de la colonia y que, aunque se habían visto alteradas durante el proceso de construcción de los Estados nacionales, continuaron e indudablemente se resintieron luego de la contienda ${ }^{4}$.

La recuperación de los años de la Primera Guerra Mundial, aunque supuso una ligera recuperación de las importaciones, no comportó cambios estructurales significativos ni en Chile ni en Perú (Albert, 1988; Badia-Miró y Ducoing, 2015; Muñoz Gomá, 1988; Zegarra, 2017). La expansión de la manufactura en los países latinoamericanos como respuesta a las restricciones en el comercio exterior no se consolidó en la mayoría de

\footnotetext{
${ }^{3}$ Esos trabajos son completados con las evidencias de Sugihara (1990, 2005).

${ }^{4}$ Sobre las relaciones comerciales existentes en la zona del Alto Perú, Bolivia y Chile durante la colonia ver Langer y Conti (1991).
}

Estados latinoamericanos, con la excepción de Argentina (Villanueva, 1972 $)^{5}$

A diferencia de lo ocurrido en Chile, Perú mostró una mayor estabilidad, manteniendo el comercio regional en niveles que oscilaban alrededor del $20 \%$. Las lagunas en la información comercial peruana se corresponden con importantes episodios bélicos que tuvieron graves secuelas en la economía, la política y la sociedad. La Guerra del Pacífico certificó el fin del auge del guano y la pérdida de las exportaciones de nitratos. Sin embargo, tras la guerra civil de 1894-1895, la economía consolidó un modelo exportador basado en la variedad regional de sus recursos naturales. La composición por productos de la exportación de Perú destacó en el contexto latinoamericano por su diversificación, característica que compartió con países como México y Argentina (Badia-Miró, Carreras-Marín y Rayes, 2016; Kuntz, 2010; Zegarra, 2017). Esa situación le diferenciaba del resto de países vecinos, los cuales sufrían una extrema especialización comercial basada en un único producto de exportación. En concreto, Perú tenía una estructura de exportación bastante diversificada que abarcaba desde lana, caucho, azúcar, algodón, metales y, posteriormente, petróleo a los mercados externos, lo que le ha llevado a ser calificada como economía «multiexportadora» (Drinot, 2000).

A partir de las evidencias recogidas, podemos afirmar que la economía chilena y peruana fueron un ejemplo de menor integración regional en un contexto, el latinoamericano, que se caracterizaba por tener unos niveles muy reducidos de integración regional. La inserción de ambos países en los mercados internacionales impulsó un proceso de concentración en los destinos que se fue acentuando con el paso de los años, tomando la forma de una extrema especialización productiva (como en el caso chileno) o de mucha más diversificación (como en el caso pe-

\footnotetext{
${ }^{5}$ Williamson (2010) confirma esa falta de dinamismo de la industria latinoamericana, sobre todo cuando se compara con lo observado en otras regiones de la periferia económica y, por supuesto, de Japón.
} 
ruano). Entre los motivos que hubo detrás de ese proceso estaría la lejanía a los principales mercados de la costa atlántica latinoamericana y la quiebra que supuso para los mercados regionales la Guerra del Pacífico. Ambos elementos frenaron el tradicional comercio de manufacturas tradicionales que se remontaba a la época colonial (Assadourian, 1982; Peres-Cajías et al., 2021).

Los datos porcentuales nos permiten confirmar la importancia del comercio regional a fines del siglo xIx y el posterior cambio de tendencia con el inicio de siglo xx. Además, ese ligero repunte porcentual fue resultado de un intenso crecimiento en los valores absolutos, resultado de una intensa recuperación, tanto en el caso de Chile como en el caso de Perú (en un contexto de una considerable expansión de las exportaciones totales).

En el caso japonés, los porcentajes no diferían mucho de los peruanos hasta 1890, aunque a partir de ese momento el comercio regional se incrementó hasta alcanzar un 40\%. Para entender esta divergencia, en primer lugar cabe destacar que el peso de los británicos y de los norteamericanos como destino de las exportaciones de Japón nunca tuvo la importancia que llegó a tener para las exportaciones chilenas y peruanas. De ello se desprende una mayor tendencia a la diversificación geográfica en el caso japonés (véase figura 6). Si vamos al detalle, si bien en la década de los 1870 observamos niveles parecidos (alrededor del $50 \%$ para Japón y del 60\% en el caso de Chile), el inicio del ciclo del salitre supuso una expansión importante en el caso chileno, llegando a sobrepasar el $80 \%$, mientras que en el caso del país asiático la tendencia fue decreciente, llegando a caer por debajo del $40 \%$ antes de la Primera Guerra Mundial. En el caso de las importaciones, la dependencia era, si cabe, aún más marcada y con una trayectoria divergente (véase figura 7). En los primeros años analizados, la dependencia nipona de las importaciones desde los EE. UU. y el Reino Unido superaba a la

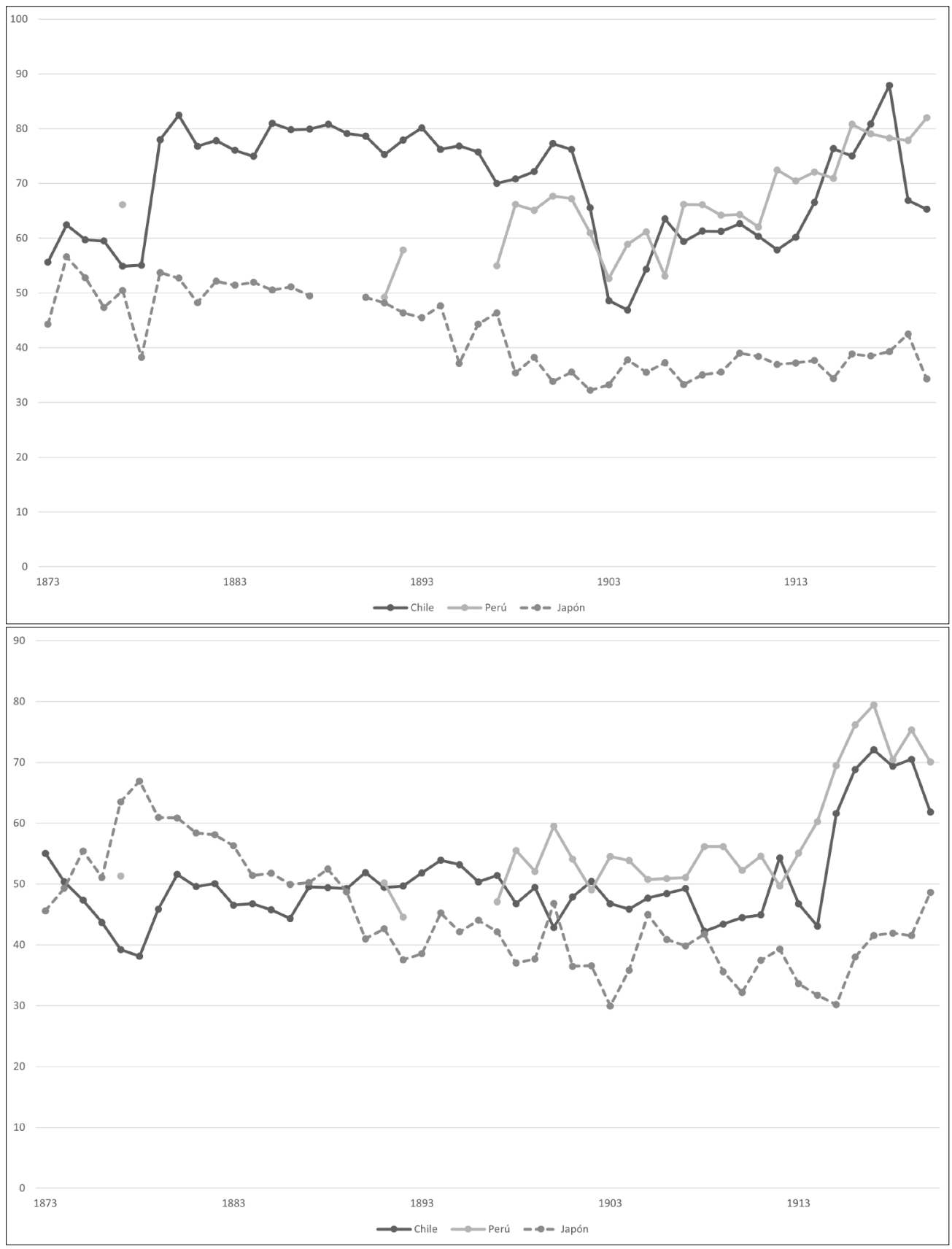

Figura 6. El comercio de Japón, Chile y Perú con los EEUU y Reino Unido (\% sobre la exportación).

Fuente: elaboración propia en base a estadísticas comerciales oficiales de cada uno de los países. Para más detalles, véase la lista de referencias de fuentes que aparecen en la bibliografía.

Figura 7. El comercio de Japón, Chile y Perú con los EE. UU. y Reino Unido (\% sobre la importación).

Fuente: elaboración propia en base a estadísticas comerciales oficiales de cada uno de los países. Para más detalles, véase la lista de referencias de fuentes que aparecen en la bibliografía. 
de Chile. Sin embargo, Japón acabaría en niveles alrededor del $40 \%$, mientras que Chile y Perú sobrepasaban el $70 \%$.

Una parte de las diferencias observadas en ambas regiones se explicaría por la existencia de reexportaciones. Si bien es verdad que en Asia el comercio directo de las colonias europeas con las metrópolis no era tan elevado como en el caso latinoamericano, también es cierto que hay que considerar que gran parte del comercio intraasiático recogería y alimentaría flujos comerciales con destino o procedencia de colonias europeas, principalmente británicas, que eran centros de reexportación. En ese sentido, el resultado que encontramos estaría en la línea de lo que Mitchener y Weidenmier (2008) señalan cuando demuestran que la pertenencia a un imperio colonial mostraba una intensificación del comercio en el período 1870-1913, independientemente de quien fuese la metrópoli. Por tanto, en la comparación que estamos realizando no se puede soslayar que América Latina era una región con estados independientes mientras que Asia era uno de los focos del imperialismo desde finales del siglo xix. Es decir, las metrópolis no comerciaban directamente, sino que lo hacían lateralmente vía sus colonias $\mathrm{y}$, asimismo, se beneficiaban de los ventajosos acuerdos diplomáticos y comerciales firmados con Corea, China o Japón. Pese a ese posible sesgo, podemos seguir afirmando que el país asiático contaba con una mayor integración regional con sus vecinos.

En el caso de Japón, las relaciones exteriores durante la segunda mitad del siglo xix estaban reguladas por el sistema de tratados desiguales impuesto por las potencias extranjeras occidentales (Gordon, 2003). Las implicaciones económicas del mantenimiento de este sistema eran múltiples. Por ejemplo, como consecuencia de éste, hasta finales de la década de los años 1880 el $80 \%$ del comercio exterior de Japón estaba en manos de empresas y empresarios extranjeros, mientras que las industrias locales tradicionales estaban completamente expuestas a unos productos extranjeros mucho más competitivos dado que el régimen tarifario era de los más bajos del mundo. Ante esta realidad económicamente dañina y políticamente considerada como humillante, el Gobierno Meiji centró todos sus esfuerzos en la derogación de esos tratados. Con dicha finalidad, se consideraba que la vía más idónea para hacerlo debía ser que el país se convirtiese en un Estado moderno, comparable a los europeos desde el punto de vista de la institucionalidad política (sistema parlamentario bicameral, constitución monárquica, Ejército basado en el sistema de reclutamiento, educación universal obligatoria, etc..) y, por otro lado, llevar a cabo un proceso de industrialización bajo la denominada política de Fukoku kyōhei o «enriquecimiento del país, fortalecimiento del Ejército".

El papel de la política económica de los sucesivos gobiernos japoneses de los períodos Meiji, Taishō y Shōwa ha sido el factor explicativo clásico del exitoso proceso de industrialización e internacionalización de la economía japonesa desde finales del siglo xix hasta la Segunda Guerra Mundial (Lockwood, 1954). Desde esta perspectiva, la participación del Estado sería uno de los factores claves detrás de dicho éxito, tratándose de gobiernos de carácter autoritario cuyas políticas económicas eran la consecuencia de respuestas a necesidades del momento o a intentos de dar algún tipo de respuesta a determinados grupos de interés del sector privado, y no a una industrialización planificada como tal.

A partir de 1885 el país inició el despegue económico con una política industrial que, por ejemplo, permitió la creación de más de setenta empresas vinculadas a la industria textil o, también, la aparición de las primeras empresas en sectores vinculados a la industria militar de municiones, armamento y construcción de barcos. Conforme se consolidaron estos procesos, la composición y dirección de su comercio empezó a variar. Las interpretaciones tradicionales sobre la emergencia de Japón como potencia económica regional han puesto siempre el énfasis en esta política industrial, centrando la argumentación en el papel del Estado en sectores clásicos del desarrollo industrial como el ferrocarril, el sector naviero o la industria textil (Smith, 1955). Pero lo cierto es que durante las décadas finales del siglo xix su participación en el conjunto de la economía todavía era baja, mientras que los sectores tradicionales seguían conformando una parte sustancial de la canasta exportadora (Makimura, 2017). Si tenemos en cuenta esta realidad, es posible plantear que el papel de la política económica en materia de comercio exterior fue muy relevante, e incluso previo al de la política industrial en el proceso de transformación de Japón en una potencia económica. Esto explicaría, por ejemplo, el crecimiento de las exportaciones de seda y de té entre 1885 y finales del del siglo xIx, cuando dichas exportaciones se doblaron, en un momento en el que el proceso industrializador todavía se encontraba en sus inicios.

En relación con dicha orientación exterior de la política económica, el Gobierno Meiji se encargó de llevar a cabo una tarea de prospección de mercados, promoción de productos japoneses y ayudas a navieras y empresas japonesas. Con el objetivo de analizar la realidad de mercados extranjeros, el Gobierno envió a representantes oficiales a diferentes lugares de Asia para que realizasen informes sobre la presencia de productos japoneses en los respectivos mercados y las posibilidades existentes para que otros bienes y manufacturas japonesas se pudiesen adaptar a dichos mercados (Howe, 1996; Morck y Nakamura, 2007). Estos informes también servían para valorar la necesidad o no de abrir una representación permanente en aquel lugar mediante la apertura de un consulado. En caso afirmativo, los representantes oficiales destinados también se encargaban de enviar al extranjero una amplia variedad de productos para su exhibición, incluyendo no solo la seda y el té, sino también artículos tales como arroz, trigo, cáñamo, tabaco, alcanfor, soja y otros (Martínez-Taberner, 2017). Asimismo, el Gobierno Meiji financió y concedió subvenciones a sociedades mercantiles y navieras como la Kiritsu Kōshō kaisha o la Nippon Boeki Shokai (Wray, 1984).

Desde finales de los años 1890 se inició un todavía incipiente proceso por el cual las exportaciones de materias primas, a pesar de su crecimiento, disminuyeron dentro del volumen total y aumentaron las exportaciones de productos manufacturados. Japón pasó de tener una balanza comercial claramente basada en las exportaciones de seda y té y las importaciones de manufacturas, a tener una balanza comercial caracterizada por las exportaciones de manufacturas ligeras, materias primas y, todavía de forma puntual, exportaciones de la industria pesada. En lo que se refiere a los mercados de destino, los mercados asiáticos empezaron a ganar peso en el valor total de las exportaciones japonesas y desde 1898 siempre estuvieron por encima del $39 \%$ del total de las exportaciones niponas, en detrimento del porcentaje de las exportaciones a Europa y EE. UU. Por tanto, se aprecia una diversificación de las exportaciones y una diversificación geográfica de los mercados de destino. 
Si la política comercial explicada con anterioridad había contribuido al inicio de un proceso de sustitución de exportaciones, incluso con anterioridad a la obtención de la independencia comercial y económica que supuso la derogación de los tratados desiguales a principios del siglo xx, el imperialismo colonial nipón iniciado desde 1895 se había convertido en un nuevo catalizador del proceso de industrialización, favoreciendo a su vez el proceso de integración comercial regional. El comercio regional suponía una gran oportunidad para un Japón que cada vez se veía más necesitado de impulsar su política comercial porque muchas de sus nuevas industrias requerían materias primas y energía del extranjero, así como nuevos mercados para sus productos. Esta necesidad se encontraría entre la miríada de factores que motivaron la colonización de Taiwán en 1895, tras la victoria en la primera guerra sino-japonesa de 1894-1895, y la ocupación colonial de la península coreana en el año 1910. En ambas colonias Japón aplicó planes de desarrollo agrario, los cuales impulsaron la producción agrícola para el consumo doméstico en Japón y la creación de mercados para las exportaciones de productos industriales hechos en Japón, de forma que podía obtener productos agrícolas y materias primas a precios bajos y fomentar la exportación de productos industriales de sectores como el textil, el químico o, cada vez más, la industria pesada (Hamashita, 2008; Perkins y Tang, 2017; Schran, 1994).

La estrategia de creación de un imperio con una marcada política colonial se unió a la política comercial y la política industrial del Gobierno japonés, favoreciendo su ascensión como una potencia económica cada vez más integrada regionalmente y, también, cada vez más dependiente del mercado asiático. De esta forma, Japón representó una excepción, dado que los países del sudeste Asiático y de Asia oriental, que no tuvieron gobiernos independientes, no fueron capaces de llevar una estrategia industrializadora, una política comercial y una política colonialista, sino que mantuvieron la dependencia de importaciones de países occidentales y cada vez más de importaciones de Japón, y siguieron especializándose en la exportación de productos clásicos del sector agroexportador hasta la Segunda Guerra Mundial (Sugihara, 2005). La comparación entre el caso japonés y de las islas Filipinas es un ejemplo claro de esta tendencia descrita. Mientras que el primero explotó toda su capacidad exportadora y se industrializó con el apoyo del Gobierno, pudiendo así aumentar el valor añadido de los bienes exportados a los mercados de Asia, las exportaciones de las islas Filipinas se concentraron en los productos agrícolas como el azúcar (Martínez-Taberner, 2017).

Por tanto, aunque hasta la Primera Guerra Mundial podemos afirmar que Japón tuvo una economía dual, combinándose un fuerte sector agrícola con una industrialización incipiente, desde finales del siglo xix esa industrialización se intensificó orientándose hacia los mercados vecinos. Es decir, el país experimentaba un proceso de industrialización que trataba de competir, en la medida de sus posibilidades, con los países occidentales en la venta de productos y en el acceso a las materias primas en la región de Asia oriental y en el sudeste Asiático, sumando sectores de baja productividad y bajo precio, aprovechándose de su ventaja comparativa, una mano de obra muy barata y la disponibilidad de mercados cercanos (Meissner y Tang, 2018). Como muestra el Annuaire Financier et Economique du Japon, conforme finaliza el siglo xix los mercados asiáticos fueron cada vez más importantes en la balanza comercial exterior nipona. Un proceso que se vio muy reforza- do a partir de las victorias militares japonesas y, sobre todo, la adquisición de nuevas colonias en el Pacífico,

Este proceso se consolidó definitivamente durante la Primera Guerra Mundial. La Gran Guerra trajo un auténtico despegue económico para Japón. La retirada de los productos europeos - principalmente británicos- de los mercados asiáticos, especialmente en China, crearon enormes oportunidades para los productos de las empresas japonesas fruto de la industrialización de una parte de la economía, especialmente del sector textil y otras manufacturas. No fue solo la industria ligera, sino que otras empresas japonesas de la industria pesada, pertenecientes a los denominados zaibatsu como Sumitomo o Mistui, pudieron aprovecharse de la demanda de maquinaria, municiones, productos químicos, hierro o acero de los países aliados. También las empresas navieras japonesas se beneficiaron de las exportaciones a Asia. Tras la Primera Guerra Mundial, las importaciones de materias primas eran más importantes que las importaciones de manufacturas, mientras que las manufacturas ya representaban el $90 \%$ de las exportaciones. Esa evolución es distinta a la observada en el caso latinoamericano, donde únicamente se observó un tímido proceso de sustitución de importaciones durante la Primera Guerra Mundial. A diferencia de ello, Japón, había conseguido impulsar una industrialización basada en las exportaciones de manufacturas a los mercados regionales (Ayuso-Díaz y Tena-Junguito, 2020; Ōkawa, Shinohara y Meissner, 1979).

\section{Conclusiones}

La integración de las economías periféricas en la economía internacional durante la Primera Globalización se inició con una fuerte expansión del comercio con los países europeos. Sin embargo, el devenir de la integración regional en la zona de Asia-Pacífico y América Latina, pese a tener comportamientos parecidos al principio, siguieron una trayectoria muy desigual a partir de los años finales del siglo xix. En el caso de la región asiática, el proceso se intensificó significativamente en paralelo a la aparición de Japón como nueva potencia industrial. Por el contrario, en América Latina el proceso de integración de esos países en la economía mundial se hizo totalmente al margen de la integración regional. De hecho, Perú y Chile experimentaron un proceso de desintegración regional, marcado por un proceso de desaparición de exportaciones de manufacturas tradicionales a los mercados vecinos. Estos lazos previos existentes se fueron debilitando, tanto por la conflictividad existente entre los antiguos socios comerciales como por la falta de competitividad de los productos manufacturados. Este problema se agudizó a medida que la industrialización incipiente se iba encontrando con dificultades, tanto para vender los productos manufacturados en los mercados domésticos como en el acceso a los mercados regionales. Las razones detrás de esas trayectorias divergentes fueron diversas. En este artículo, de manera complementaria a los factores introducidos por otros autores, enfatizamos la importancia que tuvo la existencia de diferencias importantes entre el potencial de mercado de ambas regiones. Es decir, planteamos que, dado que Japón contaba con un potencial de mercado mucho mayor $\mathrm{y}$ unos menores costes de transporte con sus vecinos, pudo aprovechar esos mercados cercanos para afianzar su proceso de desarrollo manufacturero a través del reforzamiento del proceso de integración regional a medida que las potencias coloniales occidentales, tradicionales proveedores en esas re- 
giones, iban quedando relegadas. Este factor supuso un complemento importante al fortalecimiento progresivo de la demanda doméstica. A su vez, la necesidad de cubrir la creciente demanda de materias primas vinculada al proceso industrializador aumentó sensiblemente el peso de las importaciones regionales.

\section{Fuentes oficiales}

Annuaire Financier et Économique du Japon. 1903. Ministere des Finances.

Annuaire Financier et Économique du Japon. 1916. Ministere des Finances.

Annuaire Financier et Économique du Japon. 1922. Ministere des Finances.

Anuario del Comercio Exterior del Perú. II Parte. Años 19451946. República del Perú. Departamento de Estadística General de Aduanas. Callao.

Anuario del Comercio Exterior del Perú. I Parte. Años 19451946. República del Perú. Departamento de Estadística General de Aduanas. Callao.

Anuario del Comercio Exterior del Perú correspondiente a 1936. República del Perú. Departamento de Estadística General de Aduanas. Callao. Marzo, 1937.

Anuario Estadístico de Chile. 1862-1863 (351)

El comercio hispano-peruano, su realidad y sus posibilidades. Por Antonio Pinilla Rambaud. Consul de España. Cámara Oficial Española de Comercio del Perú. Lima 1924.

Estadística Comercial de la República de Chile. 1914

Estadística Comercial de la República de Chile. 1915

Estadística Comercial de la República de Chile. 1916

Estadística Comercial de la República de Chile. 1917

Estadística Comercial de la República de Chile. 1918

Estadística Comercial de la República de Chile. 1919

Estadística Comercial de la República de Chile. 1920

Extracto Estadístico del Perú 1923. Ministerio de Hacienda y

Comercio, Lima, Casa Editora La Opinión Nacional, 1924.

Mitchell (International Historical Statistics: The Americas 1750-2000).

Portocarrero Suárez, F., Beltrán Barco, A. y Romero Pinillos. M. E. (1992). Compendio estadístico del Perú, 1900-1990. Universidad del Pacífico.

Statistical Abstract for the Principal and Other Foreign Countries in Each Year from 1873 to 1882-1883.

Statistical Abstract for the Principal and Other Foreign Countries in Each Year from 1882 to 1891-1892.

Statistical Abstract for the Principal and Other Foreign Countries in Each Year from 1890 to 1899-1900.

Statistical Abstract for the Principal and Other Foreign Countries in Each Year from 1901 to 1912.

Statistical Abstract of Foreign Countries Parts I-III. Statistics of Foreign Commerce. October, 1909. Washington Government Printing Office.

\section{Bibliografía}

Abreu, M. de P. y Bevilaqua, A. (1996). «Brazil as an export economy, 1880-1930», en Cárdenas, E. Ocampo, J. A. y Thorp, R. (eds.). An Economic History of Twentieth-Century Latin America. London: Palgrave Macmillan, pp. 32-54.
Albert, B. (1988). South America and the First World War: the impact of the war on Brazil, Argentina, Peru and Chile. Cambridge: Cambridge University Press.

Assadourian, C. S. (1982). El sistema de la economía colonial: mercado interno, regiones y espacio económico. Lima: Instituto Estudios Peruanos.

Ayuso-Díaz, A. y Tena-Junguito, A. (2020). "Trade in the shadow of power: Japanese industrial exports in the interwar years», Economic History Review, 73 (3), 815-843.

Badia-Miró, M. (2015). «The evolution of the location of economic activity in Chile in the long run: A paradox of extreme concentration in absence of agglomeration economies», Estudios de Economía 42, 143-167.

Badia-Miró, M. y Carreras-Marín, A. (2012). «Latin America and its main trade partners (1860-1930): Did WWI affect geographical patterns?», en Yañez, C. y Carreras, A. (eds.). The Economies of Latin America: New Cliometric Date, London: Perspectives in Economic and Social History. Pickering and Chatto Publishers, pp. 59-68.

Badia-Miró, M., Carreras-Marín, A. y Meissner, C. M. (2018). «Geography, policy, or productivity? Regional trade in five South American countries, 1910-50», Economic History Review, 71, 236-266.

Badia-Miró, M., Carreras-Marín, A. y Rayes, A., (2016). «La diversificación del comercio de exportación latinoamericano, 1870-1913. Los casos de Argentina, Chile y Perú», en Lopes, M. A. y Zuleta, M. C. (eds.). Mercados en común. Estudios sobre conexiones transnacionales, negocios y diplomacia en las Américas (siglos XIX y Xx). México DF: El Colegio de México, pp. 45-77.

Badia-Miró, M. y Díaz-Bahamonde, J. (2017). «The Impact of Nitrates on the Chilean Economy, 1880-1930», en Kuntz Ficker, S. (ed.). The First Export Era Revisited. Reassessing its Contribution to Latin American Economies. Cham: Palgrave Macmillan, pp. 153-190.

Badia-Miró, M. y Ducoing, C. A. (2015). «The long run development of Chile and the Natural Resources curse. Linkages, policy and growth, 1850-1950», en Badia-Miró, M., Pinilla, V. y Willebald, H. (eds.). Natural Resources and Economic Growth: Learning from history. London: Routledge, pp. 204-225.

Bermúdez, O. (1963). Historia del salitre: desde sus orígenes hasta la Guerra del Pacífico. Santiago de Chile: Publicaciones Universidad de Chile.

Bértola, L. y Ocampo, J. A. (2012). The Economic Development of Latin America since Independence. Oxford: Oxford University Press.

Bulmer-Thomas, V. (2010). La historia económica de América Latina desde la independencia. México DF: Fondo de Cultura Económica.

Cardoso, F. H. y Faletto, E. (1971). Dependencia y desarrollo en América Latina: ensayo de interpretación sociológica. México: Siglo XXI Editorial.

Cariola Sutter, C. y Sunkel, O. (1983). Un siglo de historia económica de Chile 1830-1930: dos ensayos y una bibliografía. Madrid: Cultura Hispánica.

Carreras-Marín, A., Badia-Miró, M. y Peres Cajías, J. (2013). «Intraregional Trade in South America, 1912-1950: The Cases of Argentina, Bolivia, Brazil, Chile and Peru", Economic History of Developing Regions, 28, 1-26.

Contreras, C. (2009). «Política demográfica, crecimiento económico y formación del mercado laboral en el Perú del siglo veinte», Investigaciones de Historia Económica, 13 (5), 11-41.

Cortés-Conde, R. y Hunt, S.J. (1985), The Latin American economies: growth and the export sector, 1880-1930. New York; London: Holmes and Meier.

Devlin, R. y Ffrench-Davis, R. (1999). «Towards an Evaluation of Regional Integration in Latin America in the 1990s», World Economy, 22, 261-290.

Dos Santos, T. (1970). «The Structure of Dependence», American Economic Review, 60, 231-236.

Drinot, P. (2000). «Peru, 1884-1930: A Beggar Sitting on a Bench of Gold?», en Cardenas, E., Ocampo, J. A. y Thorp, R. (eds.). An Economic History of Twentieth-Century Latin America. Oxford: Palgrave, pp. 152-187.

Duran, X., Musacchio, A. y Della Paolera, G. (2017). «Industrial growth in South America. Argentina, Brazil, Chile and Colombia, 18902010», en O'Rourke, K. H. y Williamson, J. G. (eds.). The Spread of 
Modern Industry to the periphery since 1871. Oxford: Oxford University Press, pp. 318-342.

ECLAC (1998). Regional integration in Latin America, globalization and south-south trade. Santiago de Chile: Economic Commission for Latin America and the Caribbean.

Findlay, R. y O'Rourke, K. H. (2007). Power and Plenty: Trade, War and the World Economy in the Second Millennium. Princeton: Princeton University Press.

Gómez-Galvarriato, A. y Williamson, J. G. (2009). «Was It Prices, Productivity or Policy? Latin American Industrialisation after 1870», Journal of Latin American Studies, 41, 663-694.

Gordon, A. (2003). A modern history of Japan: From Tokugawa times to the present. New York: Oxford University Press.

Hamashita, T. (2008). China, East Asia and the global economy: regional and historical perspectives. New York: Routledge.

Harris, C. D. (1954). "The market as a factor in the localization of industry in the United States", Annals of the Association of American Geographers, 44, 315-348.

Howe, C. (1996). The Origins of Japanese Trade Supremacy: Development and Technology in Asia from 1540 to the Pacific War. Chicago: University of Chicago Press.

Jacks, D. S. y Novy, D. (2018). «Market Potential and Global Growth over the Long Twentieth Century», Journal of International Economics, 114, 221-237.

Kuntz-Ficker, S. (2010). Las exportaciones mexicanas durante la primera globalización (1870-1929). México DF: El Colegio de México.

Kuntz-Ficker, S. (2017). The First Export Era Revisited. Reassessing its Contribution to Latin American Economies. Oxford: Palgrave Macmillan.

Langer, E. D. D. y Conti, V. E. E. (1991). «Circuitos comerciales tradicionales y cambio económico en los Andes Centromeridionales (18301930)», Desarrollo Económico, 31, 91-111.

Latham, A. J. H. (1994). «The Dynamics of Intra-Asian Trade, 1868-1913: The Great Entrepots of Singapore and Hong Kong», en Latham, A. J. H. y Kawakatsu, H. (eds.). Japanese Industrialization and the Asian Economy, London: Routledge, pp. 145-171.

Lockwood, W. W. (1954). The economic development of Japan: Growth and structural change, 1868-1938. Princeton: Princeton University Press.

Makimura, M. (2017). Yokohama and the Silk Trade: How Eastern Japan Became the Primary Economic Region of Japan, 1843-1893, Lanham: Lexington Books.

Martínez-Taberner, G. (2017). El Japón Meiji y las colonias asiáticas del imperio español. Barcelona: Ediciones Bellaterra.

Meissner, C. M. y Tang, J. P. (2018). «Upstart Industrialization and Exports: Evidence from Japan, 1880-1910», Journal of Economic History, 78, 1068-1102.

Mesquita Moreira, M., Volpe, C., Blyde, J. S. y Martincus Volpe, C. (2008). Unclogging the Arteries. The Impact of Transport Costs on Latin American and Caribbean Trade. Washington: David Rockefeller Center for Latin American Studies.

Mitchener, K. J. y Weidenmier, M. (2008). "Trade and Empire», The Economic Journal, 118, 1805-1834.

Morck, R. y Nakamura, M. (2007). «Business groups and the big push: Meiji Japan's mass privatization and subsequent growth", Enterprise and Society, 8 (3), 543-601.

Muñoz Gomá, Ó. (1988). Chile y su industrialización. Pasado, crisis y opciones. Santiago de Chile: CIEPLAN.
O’Rourke, K. H. y Williamson, J. G. (1999). Globalization and history: The evolution of a nineteenth-century Atlantic economy. Cambridge: The MIT Press.

kawa, K., Shinohara, M. y Meissner, L. (eds.). (1979). Patterns of Japanese economic development; a quantitative appraisal. New Haven: Yale University Press.

Peres-Cajías, J., Badia-Miró, M., Carreras-Marín, A. y Navarro, C. (2021). "Globalization and Natural Resource Abundance: Is Export Diversification Possible? A Comparison of Export Composition in Chile and Norway, 1870-2017», en Ducoing, C. A. y Peres-Cajías, J. A. (eds.). Natural Resources and Divergence. A Comparison of Andean and Nordic Trajectories. Palgrave Macmillan, pp. 9-40.

Perkins, D. H. y Tang, J. P. (2017). «The Spread of Modern Industry to the Periphery since 1871», en O'Rourke, K. H. y Williamson, J. G. (eds.). The Spread of Modern Industry to the Periphery since 1871. New York: Oxford University Press, pp. 169-196.

Rayes, A. (2015). «La estadística de las exportaciones argentinas, 18751913. Nuevas evidencias e interpretaciones», Investigaciones de Historia Economica, 11 (1), 31-42.

Restrepo Estrada, M. I. (2017). Regional trade integration and industrialization. Colombia and South America in the first half of the 20th Century [tesis doctoral]. Universidad Carlos III de Madrid, Madrid.

Salvucci, R. (2008). «Export-led growth industrialization», en Bulmer-Thomas, V., Coatsworth, J. H. y Cortés-Conde, R. (eds.), The Cambridge Economic History of Latin America. Cambridge: Cambridge University Press, pp. 249-292.

Sater, W. F. (1986). Chile and the War of the Pacific. Lincoln: University of Nebraska Press.

Schran, P. (1994). "Japan's East Asia Market», en Latham, A. J. H. y Kawakatsu, H. (eds.). Japanese Industrialization and the Asian Economy. London: Routledge, pp. 145-171.

Seminario, B. (2015). El desarrollo de la economía peruana en la era moderna. Lima: Universidad del Pacífico.

Smith, T. C. (1955). Political Change and Industrial Development in Japan: Government Enterprise, 1868-1880. Stanford: Stanford University Press.

Sugihara, K. (1990). "Japan as an engine of the Asian international economy, c. 1880-1936», Japan Forum, 2, 127-145.

Sugihara, K. (ed.). (2005). Japan, China, and the Growth of the Asian International Economy, 1850-1949. Oxford: Oxford University Press.

Sugiyama, S. (1988). «Textile Marketing in East Asia, 1860-1914», Textile History, 19, 279-298.

Tsunoyama, S. (1994). «Sino-Japanese Trade and Japanese Industrialization", en Latham, A. J. H. y Kawakatsu, H. (eds.). Japanese Industrialization and the Asian Economy. London: Routledge, pp. 145-171.

Villanueva, J. (1972). "El origen de la industrialización argentina», Desarrollo Económico, 12, 451-476.

Williamson, J. G. (2010). When, where, and why? Early industrialization in the poor periphery 1870-1940. NBER Working Paper Series, 16809.

Wray, W. (1984). Mitsubishi and the N.Y.K., 1870-1914: BusinessStrategy in the Japanese Shipping Industry. Boston: Harvard University Press.

Zegarra, L. F. (2011). "Transport costs and economic growth in a backward economy: the case of Peru, 1820-1920», Revista de Historia Económica, 29, 361-392.

Zegarra, L. F. (2017). «Exports and Their Impact on the Economy. The Case of Peru, 1830-1930», en Kuntz-Ficker, S. (ed.). The First Export Era Revisited. Reassessing its Contribution to Latin American Economies. Palgrave Macmillan, pp. 277-312. 